\title{
CHANGE BLINDNESS, ATTENTION, AND DRIVING PERFORMANCE
}

\author{
Monica N. Lees, JonDavid Sparks, John D. Lee, Matthew Rizzo \\ University of Iowa \\ University of Iowa Carver College of Medicine \\ Iowa City, Iowa, USA \\ E-mail: mnlees@engineering.uiowa.edu
}

\begin{abstract}
Summary: Concern over older driver high traffic fatality rates has resulted in an effort to identify risk factors and to develop methods of assessment. This study examines two attention-related tasks, Useful Field of View (UFOV) and Change Blindness (CB), in relation to vision and cognitive test batteries and driving performance measures collected using a simulator and an instrumented vehicle. Eight older adults with Alzheimer's disease and nine comparison subjects between 64 and 81 participated. Factor analysis results indicate that UFOV and CB relate to different factors. While UFOV relates to memory, decision-making, attention, and visual spatial ability, $\mathrm{CB}$ relates to vision and attention. The type of images used on a CB task influence how the task relates to driving performance measures. Researchers should be thoughtful when selecting images to include in $\mathrm{CB}$ tasks to maximize insight into real-world driving.
\end{abstract}

\section{INTRODUCTION}

Older drivers are overrepresented in fatal traffic accidents on a per-mile basis (Bedard, Guyatt, Stones, \& Hirdes, 2002). Yet, the majority of older drivers remain crash-free. Because it would be unfair to restrict driving privileges based solely on age, there is a growing effort to understand the factors that increase crash risk and to identify metrics for identifying unsafe drivers.

Failure to detect relevant changes may impede driver reactions in dynamic visual environments. Change blindness (CB) is an inability to detect large changes in a visual scene, often in association with a visual disruption, such as an eye-movement, blink, or film cut (McCarley et al., 2004; O'Regan, Rensink, \& Clark, 1999; Pringle, Irwin, Kramer, \& Atchley, 2001; Rizzo et al., submitted). Recent findings suggest that noticing changes requires both attention and visual working memory, the ability to store and compare visual information before and after a change occurs (Pringle et al., 2001; Simons \& Ambinder, 2005). Older adults show reduced speed and accuracy on CB tasks compared to younger adults (Caird, Edwards, Creaser, \& Horrey, 2005; Pringle et al., 2001; Rensink, 2002). The degree of task difficulty depends on the eccentricity, meaningfulness, and salience of the changing object (Pringle et al., 2001). While CB studies have included traffic scenes, this study directly tests the hypothetical relationship between CB using traffic scenes and actual driving performance.

The useful field of view (UFOV) is another attention-related construct, operationalized as the area from which visual information can be extracted during a single glance without moving the eyes or head (Sanders, 1970). UFOV scores are influenced by visual sensory function, visual processing speed, divided attention, and selective attention. Several studies have shown that the 
UFOV test correlates with visual/cognitive tests and can successfully predict driving performance, measured by state crash records, on-road driving tests, and driving simulator performance (Ball \& Owsley, 1993; Goode et al., 1998; Myers, Ball, Kalina, Roth, \& Goode, 2000; Roenker, Cissell, Ball, Wadley, \& Edwards, 2003).

This study examines the underlying features of these two tasks in relation to commonly used vision and cognitive test batteries, and driving performance measures assessed using a simulator and an instrumented vehicle.

\section{METHOD}

\section{Participants}

Seventeen elderly individuals participated in the study. Eight participants with early AD (74 - 81 years, $M=77.5)$ were recruited from a registry in the Department of Neurology. Nine comparison subjects (64 - 73 years, $M=68.3$ ) without AD were recruited from the Iowa City and Coralville area. Corrective lenses were allowed during testing.

\section{Vision and Cognitive Assessment}

All participants completed a test battery examining: (1) basic vision: contrast sensitivity, acuity (2) visual-construction: judgment of line orientation (JLO), complex figure test copy version (CFT-Copy), WAIS- III block design (BLOCKS) (3) memory: complex figure test recall version (CFT-Recall), Benton visual retention test (BVRT), Rey auditory verbal learning test (AVLT) (4) decision making (executive functioning, EF): trail-making test (TMT-B), controlled oral word association (COWA) and (5) Attention: UFOV, CB.

UFOV. UFOV scores represent a composite of four subtests administered with the Visual Attention Analyzer (Model 3000, Vision Resources, Chicago, IL, Ball \& Owsley, 1993; Edwards et al., 2005). Performance on each subtest is expressed as the display duration (ms) required for a subject to achieve $75 \%$ correct. Task 1 , of visual processing speed (ms), measures how fast subjects can perform a two-alternative forced choice task presented in central fixation. Task 2 of divided attention, measures how fast the subject can concurrently identify a central and a peripheral target. Task 3, of selective attention, is the same as Task 2 but the peripheral target is surrounded by a set of distracters shapes. Subtest 4 resembles subtest 3 but presents a more difficult central task (same/different discrimination).

Change Blindness Task. The CB task was administered on a personal computer with a 21-inch touch-screen color monitor positioned approximately two feet from the participant. Table 1 lists the 21 pairs of images used. Each pair consisted of an original and a modified image (i.e., a single object in the photograph was changed). For change trials the original image transitioned into the modified image over a two-second duration (Simons, Franconeri, \& Reimer, 2000). Up to five complete changes could occur during the $10 \mathrm{~s}$ presentation time. For catch trials, a static image was presented for the entire $10 \mathrm{~s}$. Participants were instructed that an object could appear, disappear, change location, change color or not change. Participants were asked to touch the screen where the perceived change occurred or to press the space bar if no change occurred. 
Table 1. Images for change and catch trials by image type

\begin{tabular}{|c|c|c|c|c|}
\hline \multirow{2}{*}{\multicolumn{2}{|c|}{ Image Type }} & \multirow[b]{2}{*}{ Short Name } & \multicolumn{2}{|l|}{ Description } \\
\hline & & & Change Trial & Catch Trial \\
\hline Intersection Lights & \begin{tabular}{l|}
1 \\
2
\end{tabular} & $\begin{array}{l}\text { Green to Red } \\
\text { Red to Green }\end{array}$ & $\begin{array}{l}\text { Traffic lights change from green to red } \\
\text { Traffic lights change from red to green }\end{array}$ & $\begin{array}{l}\text { Traffic lights are red } \\
\text { Traffic lights are green }\end{array}$ \\
\hline Safety Sign & $\begin{array}{l}3 \\
4\end{array}$ & $\begin{array}{l}\text { Const } \\
\text { Stop }\end{array}$ & $\begin{array}{l}\text { Construction sign disappears } \\
\text { Stop sign appears }\end{array}$ & $\begin{array}{l}\text { Construction sign } \\
\text { Stop sign on left }\end{array}$ \\
\hline Information Sign & $\begin{array}{l}5 \\
6 \\
7\end{array}$ & $\begin{array}{l}\text { Town } \\
\text { Left Turn } \\
\text { Billboard }\end{array}$ & $\begin{array}{l}\text { Green town sign changes } \\
\text { Left turn only sign appears } \\
\text { Billboard sign disappears }\end{array}$ & $\begin{array}{l}\text { Green town sign } \\
\text { Left turn only sign } \\
\text { Billboard sign }\end{array}$ \\
\hline Sign on Vehicle & \begin{tabular}{r|}
8 \\
9 \\
10
\end{tabular} & $\begin{array}{l}\text { Truck } \\
\text { Bus } \\
\text { License Plate }\end{array}$ & $\begin{array}{l}\text { Sign on back of delivery truck disappears } \\
\text { Sign on bus disappears } \\
\text { License plate holder changes }\end{array}$ & $\begin{array}{l}\text { Sign on back of delivery truck } \\
\text { Sign on bus } \\
\text { License plate holder }\end{array}$ \\
\hline Vehicle & \begin{tabular}{l|}
11 \\
12 \\
13 \\
14 \\
15 \\
16 \\
17
\end{tabular} & $\begin{array}{l}\text { Intersection } \\
\text { Blue vehicle } \\
\text { Silver Vehicle } \\
\text { White Vehicle } \\
\text { Red Vehicle } \\
\text { Left-Turn Vehicle } \\
\text { Vehicle Grass }\end{array}$ & $\begin{array}{l}\text { Vehicle moves from stop light through the intersection } \\
\text { Blue vehicle appears in far left lane } \\
\text { vehicle changes from black to silver } \\
\text { White vehicle disappears } \\
\text { Red vehicle in front disappears } \\
\text { Vehicle making left turn disappears } \\
\text { Vehicle in grass disappears }\end{array}$ & $\begin{array}{l}\text { Vehicle in intersection } \\
\text { Blue vehicle in far left lane } \\
\text { Vehicle on left is silver } \\
\text { White vehicle on right } \\
\text { Red vehicle in front } \\
\text { Vehicle making left turn } \\
\text { vehicle in grass }\end{array}$ \\
\hline Pedestrian & \begin{tabular}{l|}
18 \\
19 \\
20
\end{tabular} & $\begin{array}{l}\text { Ped } \\
\text { Ped / Stop Sign } \\
\text { Yellow Helmet }\end{array}$ & $\begin{array}{l}\text { Pedestrians move from street corner to middle of street } \\
\text { Sign and pedestrian disappear } \\
\text { Person with yellow helmet disappears }\end{array}$ & $\begin{array}{l}\text { Pedestrians on street corner } \\
\text { Sign and pedestrian on right } \\
\text { Person with yellow helmet }\end{array}$ \\
\hline Other & 21 & Train & Train changes position & Train on left \\
\hline
\end{tabular}

Driving Simulator Assessment. Data were collected at $30 \mathrm{~Hz}$ using a medium-fidelity, fixed-base DriveSafety Vection Research Simulator (VRS), which consists of a fully instrumented 1994 four-door GM Saturn equipped with a 150-degree forward and 50-degree rear field of view. Fully-textured graphics were generated at a $60-\mathrm{Hz}$ frame rate and a resolution of $1024 \mathrm{x} 768$. Participants drove in a rural setting with a speed limit of $55 \mathrm{mph}$. During the drive, participants encountered a number of situations. In this paper, responses during two events are examined (1) a police car on the side of the road, and (2) an incursion vehicle that ran a stop sign. These events require drivers to detect and recognize unsafe situations, and respond in an appropriate manner. The dependent measures for the police car event included reaction time and whether the driver slowed down. The dependent measure for the incursion event was whether a crash resulted.

Instrumented Vehicle Assessment. Drivers also completed a range of tasks in an instrumented mid-size 1995 Ford Taurus station wagon. Driving data (e.g., speed, accelerator and brake pedal position) were digitized at $10 \mathrm{~Hz}$ and reduced to mean, SD, or count. On-road tasks in the IV included a route-following task (RFT), and a landmark and traffic sign identification task (LIT) (See Uc, Rizzo, \& Anderson, 2005; Uc, Rizzo, Anderson, Shi, \& Dawson, 2004). The RFT required drivers to navigate to a location based on a set of explicit verbal directions. The dependent measures of the task include (1) number of incorrect turns, (2) times lost, and (3) atfault safety errors (e.g., lane deviation, stopping/slowing in unsafe situations, unsafe intersection behavior). The LIT required drivers to look for and verbally report traffic signs and restaurants located along a one-mile four-lane roadway segment. There were 16 road signs and 13 restaurants. The dependent measures included (1) percentage of landmarks and traffic signs identified, and (2) number of at-fault safety errors.

\section{RESULTS}

A factor analysis examined associations between driving performance measures, UFOV, and CB. This analysis extracted sets of co-varying measures from performance on the vision and 
cognitive tests and driving tasks and identified three factors that accounted for $57 \%$ of variation across measures (Table 2). Attention and decision-making, 33\% of the variation, represents variables related to attention, decision-making $(\mathrm{EF})$, memory, and visual spatial ability. Considering that many of these functions are required to successfully navigate, it is not surprising that this factor also includes errors on the route-following task. Detection and evaluation, $13 \%$ of the variation, relates to vision and attentional abilities. This factor included at-fault errors during tasks in the IV and the ability to respond appropriately to the police car event in the simulator, all of which require the ability to detect and evaluate changes in the environment. Identification and intervention, $12 \%$ of the variation, represents variables related to identifying information and determining how to respond. These results suggest that UFOV may reflect multiple constructs, whereas $\mathrm{CB}$ may only have one underlying construct.

Table 2. Factor analysis of cognitive/visual tests, and driving performance measures

\begin{tabular}{|c|c|c|c|}
\hline & $\begin{array}{l}\text { Factor 1: Attention and } \\
\text { Decision-Making }\end{array}$ & Factor 2: Detection and Evaluation & Factor 3: Identification and Intervention \\
\hline Attention & UFOV $^{2}(.657)$ & $\begin{array}{l}\mathrm{CB}^{2} \text { - Response time (.756) } \\
\mathrm{CB}^{2} \text { z-score (-.649) }\end{array}$ & \\
\hline $\begin{array}{l}\text { Decision Making } \\
(E F)\end{array}$ & $\begin{array}{l}\text { COWA }^{3}(-.449) \\
\text { TMT- } \mathrm{B}^{3}(.804) \\
\text { RFT - wrong turns }(.704) \\
\text { RFT - times lost }(.716)\end{array}$ & & \\
\hline Memory & $\begin{array}{l}\operatorname{BVRT}^{3}(.624) \\
\operatorname{AVLT}^{3}(-.543)\end{array}$ & & \\
\hline $\begin{array}{l}\text { Visuoconstruction } \\
\text { ability }\end{array}$ & \begin{tabular}{|l} 
JLO $(-.713)$ \\
CFT-Recall $^{3}(-.566)$ \\
CFT-Copy $^{3}(-.372)$ \\
BLOCKS $^{3}(-.870)$ \\
\end{tabular} & & \\
\hline Vision & & \begin{tabular}{|l|} 
Visual Acuity $(.520)$ \\
Contrast Sensitivity $(-.529)$
\end{tabular} & \\
\hline \begin{tabular}{|l} 
Response \\
Selection
\end{tabular} & & \begin{tabular}{|l|} 
RFT $^{1}$ - at-fault errors $(.826)$ \\
LIT $^{1}$ - at-fault errors $(.667)$ \\
Police Car ${ }^{1}$ - response made $(.522)$
\end{tabular} & $\begin{array}{l}\text { Crash at intersection }{ }^{1}(.604) \\
\text { Police Car reaction time }{ }^{1}(-.626)\end{array}$ \\
\hline Identification & & & $\begin{array}{l}\text { LIT task performance }{ }^{2} \text { - critical signs }(.818) \text { LIT } \\
\text { task performance }{ }^{2} \text { - restaurants }(.710)\end{array}$ \\
\hline
\end{tabular}

1. Driving Task; 2.CB/UFOV; 3.Visual/cognitive task

Although UFOV is correlated with overall CB detection time $\left(\mathrm{R}^{2}=.578, p=.015\right)$ and hit-rate $\left(\mathrm{R}^{2}\right.$ $=-.668, p<.01)$, these two tests exhibit a different pattern of association with driving performance measures. As shown in Table 3, UFOV correlated with on-road performance measures related to RFT and LIT. In contrast, overall CB detection time (performance across all 21 image pairs) only correlated with one driving measure, at-fault errors during the LIT. Neither $\mathrm{CB}$ nor UFOV correlated with simulator performance on the police car and incursion tasks.

To further examine the association between driving and $\mathrm{CB}$ we examined the correlation between each of the $21 \mathrm{CB}$ image pairs and simulator and on-road driving performance measures. Due to the large set of correlations, Table 3 and Table 4 only include image pairs where either $\mathrm{CB}$ accuracy or detection time correlated with one or more driving performance measures. The results indicate that the association between $\mathrm{CB}$ and driving performance depends on the specific $\mathrm{CB}$ image pair. For instance, accuracy on detection tasks with a changing vehicle rarely correlated with driving performance measures, yet the ability to correctly detect the 
Table 3. Correlations of UFOV and time to detect change with driving performance for specific CB images

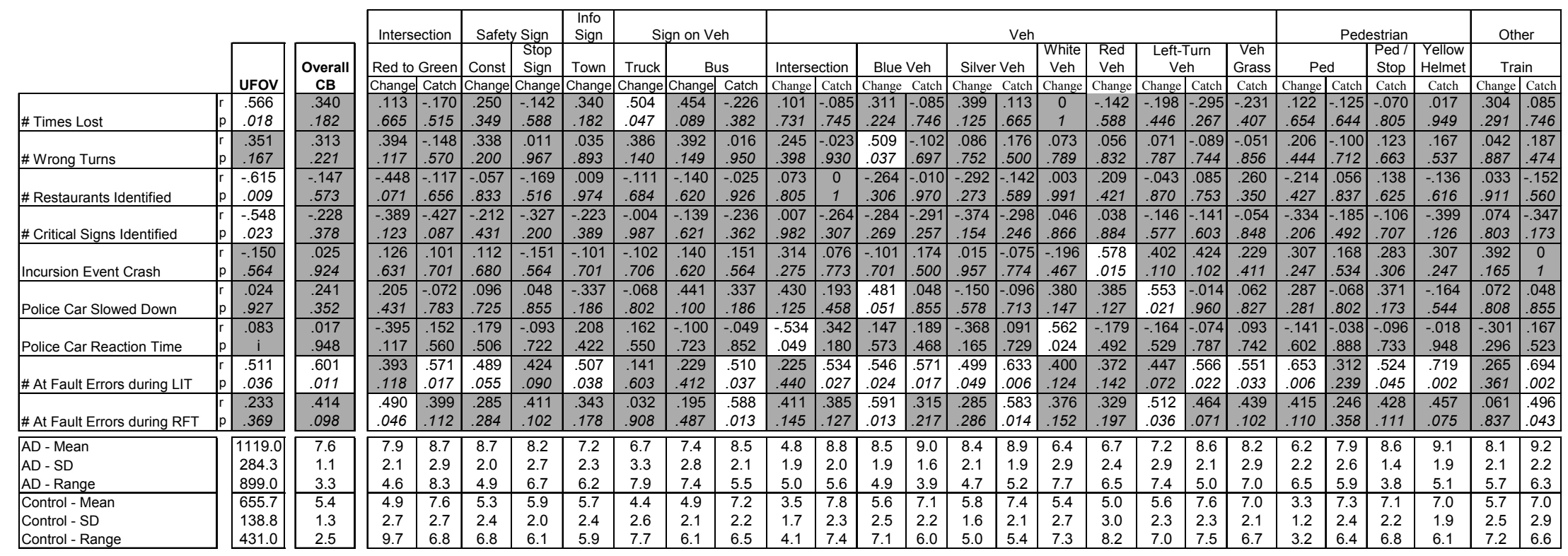

Table 4. Correlations of accuracy with driving performance for specific CB images

\begin{tabular}{|c|c|c|c|c|c|c|c|c|c|c|c|c|c|c|c|c|c|c|c|c|c|c|c|c|c|c|}
\hline & \multirow{3}{*}{$\begin{array}{l}\text { Overall CB } \\
\text { Hitrate - Correct } \\
\text { responses on } \\
\text { change trials }\end{array}$} & \multicolumn{2}{|c|}{ Intersection } & \multicolumn{2}{|c|}{ Safety Sign } & \multirow{3}{*}{\begin{tabular}{c|} 
Info \\
Sign \\
\\
Town \\
\end{tabular}} & \multicolumn{3}{|c|}{ Sign on Veh } & \multicolumn{11}{|c|}{ Vehicle } & \multicolumn{4}{|c|}{ Pedestrian } & \multicolumn{2}{|c|}{ Other } \\
\hline & & Red to & Green & Const & $\begin{array}{l}\text { Stop } \\
\text { Sign }\end{array}$ & & Truck & $\mathrm{Bu}$ & & Intersec & ction & Blue & Veh & Silver & Veh & $\begin{array}{c}\text { White } \\
\text { Veh }\end{array}$ & $\begin{array}{l}\text { Red } \\
\text { Veh }\end{array}$ & $\begin{array}{c}\text { Left- } \\
\text { Ve }\end{array}$ & & \begin{tabular}{|c|} 
Veh \\
Grass \\
\end{tabular} & $\mathrm{Pe}$ & & \begin{tabular}{|l|} 
Ped / \\
Stop \\
\end{tabular} & \begin{tabular}{|l|l} 
Yellow \\
Helmet
\end{tabular} & Tra & ain \\
\hline & & Change & & Change & & & Change & Change| & Catch & & & Change & & & & & & & & & Change & Catch & Catch & Catch & nge & Catch \\
\hline & -.368 & .171 & .182 & -.389 & -.410 & -.308 & -.545 & -.419 & -.033 & $-.194-$ & -.099 & -.182 & -.033 & -.222 & -.381 & -.218 & -.311 & 245 & .424 & -.272 & 289 & 289 & -.123 & -.222 & -.304 & 245 \\
\hline Times Lost & .146 & .512 & .484 & .136 & .103 & .230 & .029 & .120 & .901 & .507 & .704 & .484 & .901 & .409 & .131 & .417 & .225 & 343 & 102 & .326 & 277 & 278 & .662 & .409 & .290 & 343 \\
\hline & -.3 & \begin{tabular}{|l|}
-.042 \\
\end{tabular} & .149 & -.193 & -.461 & \begin{tabular}{|c|}
-.031 \\
\end{tabular} & -.537 & -.607 & -.067 & .112 & -.176 & -.352 & \begin{tabular}{|l|}
-.067 \\
\end{tabular} & .015 & -.271 & -.107 & .067 & .053 & 295 & \begin{tabular}{|l|}
-.419 \\
\end{tabular} & .048 & 328 & -.344 & -.230 & -.125 & 454 \\
\hline$\neq$ Wrong Turns & 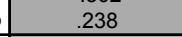 & .873 & .568 & .473 & .063 & .905 & .032 & .016 & .799 & .704 & .499 & .165 & .799 & .955 & .293 & 692 & .799 & 839 & .267 & .120 & 860 & 214 & .209 & .391 & 671 & .067 \\
\hline & 229 & \begin{tabular}{|l|}
-.378 \\
\end{tabular} & .000 & .293 & .579 & .156 & .247 & \begin{tabular}{l|l|}
.481 \\
\end{tabular} & -.084 & .098 & .147 & .134 & \begin{tabular}{|l|}
.205 \\
\end{tabular} & .164 & .134 & -.274 & 169 & .024 & \begin{tabular}{|l|}
.110 \\
\end{tabular} & .032 & .112 & 231 & .000 & 151 & .074 & \begin{tabular}{|l|l|}
.048 \\
\end{tabular} \\
\hline Reste & & .135 & \#\#\#\# & .271 & .015 & .550 & .357 & .070 & .748 & & .574 & .607 & .430 & & .607 & । & & & & & 679 & 389 & & & 801 & 854 \\
\hline & .25 & -.316 & .283 & 428 & .494 & .043 & .069 & .266 & .109 & .020 & .344 & .061 & \begin{tabular}{|l|}
.376 \\
\end{tabular} & .165 & .111 & -.276 & .097 & 109 & \begin{tabular}{|l|}
.303 \\
\end{tabular} & 191 & 127 & 369 & 079 & 221 & 300 & 133 \\
\hline \# Critical Signs Identified & 3 & .216 & .272 & .099 & .044 & .871 & .800 & .338 & .677 & .946 & .176 & .815 & .137 & .540 & .673 & .301 & .711 & 677 & .253 & 495 & 639 & 159 & 79 & 2 & .298 & 610 \\
\hline & & -.227 & -.118 & -.035 & .288 & 119 & .221 & .040 & -.203 & -.400 & -.118 & -.132 & 203 & -.051 & .132 & .16 & & .203 & \begin{tabular}{|l|}
.051 \\
\end{tabular} & .000 & .313 & 0 & -.111 & & .189 & -.044 \\
\hline Incursion Event Crash & .7 & .380 & .653 & .898 & .263 & 648 & .411 & .887 & .434 & .156 & .653 & .612 & .434 & .851 & 612 & .547 & 434 & .434 & .851 & 1.000 & .237 & 1 & .693 & .851 & .519 & 868 \\
\hline & -.0 & -.290 & .169 & 323 & -.290 & 245 & -.270 & -.764 & -.417 & .091 & -.070 & -.169 & $|-.181|$ & -.016 & -.070 & -.126 & .05 & -.181 & $\mid-.238$ & -.218 & 163 & .126 & -.218 & -.270 & 344 & 181 \\
\hline Police C & & .259 & .517 & .223 & .259 & .343 & .312 & $<.001$ & .096 & .756 & .788 & .517 & .488 & .954 & .788 & .642 & 832 & .488 & .375 & .435 & .547 & 642 & .435 & .312 & 228 & 488 \\
\hline & & -.101 & -.268 & -.102 & .050 &.- .113 & -.014 & 0 & .00 & .431 & -.122 & -.024 & \begin{tabular}{|l|}
-.048 \\
\end{tabular} & -150 & -.073 & -.45 & 337 & 289 & \begin{tabular}{|l|}
-.232 \\
\end{tabular} & .06 & .644 & .027 & 0 & 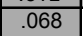 & 721 & 192 \\
\hline Police Car Reaction Time & & .701 & .298 & .706 & .848 & .665 & .960 & 1 & 1.000 & .124 & 641 & .926 & .855 & .578 & .780 & .08 & 18 & 261 & .387 & .824 & .007 & 921 & 0 & & .004 & 459 \\
\hline & -.4 & .110 & -.240 & -.407 & -.507 & \begin{tabular}{|c|}
-.062 \\
\end{tabular} & -365 & -.456 & -.210 & .000 & -.240 & -.160 & \begin{tabular}{|l|}
-.354 \\
\end{tabular} & \begin{tabular}{l|l}
-.700 \\
-.700
\end{tabular} & -.386 & .13 & -.18 & -289 & \begin{tabular}{|l|}
-.499 \\
\end{tabular} & -.326 & .078 & .555 & -326 & -.274 & -.227 & 249 \\
\hline s during LIT & 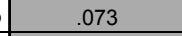 & .675 & .354 & .118 & .038 & .814 & .165 & .087 & .418 & 1.000 . & .354 & .540 & .163 & .003 & .126 & 61 & 480 & 261 & .049 & .235 & .775 & .026 & 0.235 & 0.305 & 436 & 334 \\
\hline & -.2 & .013 & -.050 & -.164 & -.603 & 101 & -294 & -.429 & -.184 & .321 & -.150 & -.262 & \begin{tabular}{|c|}
-.184 \\
\end{tabular} & -.378 & -.386 & .36 & .025 & -.381 & \begin{tabular}{|l|}
-392 \\
\end{tabular} & & .172 & 415 & & & .189 & . \\
\hline \# At Fault Errors during RFT & .398 & .961 & .849 & .543 & .010 & 699 & .270 & .110 & .479 & .264 & .567 & .310 & .479 & .149 & .126 & 165 & 925 & .0132 & 134 & 269 & . 524 & $\begin{array}{l}110 \\
110\end{array}$ & 0.269 & 0.680 & 518 & 421 \\
\hline $5-1$ & .26 & .38 & .50 & .0 & .0 & .25 & .29 & .17 & .38 & .50 & & .25 & & .29 & .3 & .43 & .38 & .13 & .50 & .29 & .29 & .13 & .29 & .29 & .17 & .25 \\
\hline & .15 & .02 & .53 & 00 & .00 & .46 & .49 & .41 & .05 & .5 & .52 & .46 & .46 & .49 & .52 & .5 & & & & & .49 & 35 & & & .41 & \\
\hline & .53 & 33 & .67 & .56 & .67 & .22 & .78 & .78 & 6 & $.8 \varepsilon$ & .78 & .56 & .78 & 78 & .78 & 4 & .6 &.$x$ & & & .4 & 58 & & & .50 & \\
\hline Control - SD & .13 & .50 & .50 & .53 & .50 & .44 & .44 & .44 & .50 & .35 & .44 & .53 & .44 & .44 & .44 & .53 & .50 & .53 & .50 & .35 & .53 & .35 & .35 & 44 & .53 & 50 \\
\hline
\end{tabular}


appearance of a stop sign correlated with multiple driving performance measures (e.g., LIT and RFT performance and at-fault errors). The range in accuracy and detection time performance across images indicates an absence of floor and/or ceiling effects (bottom of Table 3 and Table 4). Instead, the results suggest that certain situations depicted in CB trials correspond better with the types of errors drivers make. Comparison of the two tables suggests that detection time in the $\mathrm{CB}$ task corresponds better with driving performance than does $\mathrm{CB}$ accuracy.

\section{CONCLUSIONS}

Growing concern over the high traffic fatality rates of older drivers motivates effort to identify risk factors and to develop methods to assess at-risk drivers. The utility of driver assessment tests depends on how well they capture the demands of driving. In this study, we examined how UFOV and CB assessment tools correspond to driving performance of older drivers.

Three factors (attention and decision-making, detection and evaluation, and identification and intervention) were identified using a factor analysis that incorporated visual/cognitive tests, $\mathrm{CB}$, UFOV, and driving performance data. While UFOV and CB correlate with each other, they load on different factors, with UFOV relating to attention and decision-making (EF), and CB relating to detection and evaluation. These different underlying dimensions may account for the differing correlations of UFOV and CB with driving performance in the simulator and on the road. While UFOV appears to show a general relationship to driving, the association between CB and driving largely depends on the particular task images used. Given the wide range of images utilized in this experiment, eccentricity, meaningfulness, and salience are likely to have influenced the varying degree of correlation between CB and driving performance (Pringle et al., 2001). These variables are being assessed in ongoing studies of $\mathrm{CB}$ in follow-up research in our lab and others. The results suggest that specific situations/images used in a CB task are particularly relevant when trying to relate this task to driving performance measures.

Given these results, CB tasks should be refined to reflect driving situations that map more directly onto driving performance measures. Researchers should consider common crash types of specific populations and individual characteristics when determining what types of images to utilize. For example, older and younger drivers may require different stimulus sets to capture driving relevant impairments. Once refined, we believe $\mathrm{CB}$ would differentiate different driver populations and be better equipped to predict poor driving performance. Understanding the relationship between attention and driving can help identify the specific needs of drivers to better design systems that support appropriate attention allocation for demanding situations.

\section{ACKNOWLEDGMENTS}

This research was sponsored by NIA AG017177.

\section{REFERENCES}

Ball, K. K., \& Owsley, C. (1993). The useful field of view test: A new technique for evaluating age-related declines in visual function. Journal of the American Optometric Association, 64, 71-79. 
Bedard, M., Guyatt, G. H., Stones, M. J., \& Hirdes, J. P. (2002). The independent contribution of driver, crash, and vehicle characteristics to driver fatalities. Accident Analysis and Prevention, 34(6), 717-727.

Caird, J. K., Edwards, C. J., Creaser, J. I., \& Horrey, W. J. (2005). Older driver failures of attention at intersections: using change blindness methods to assess turn decision accuracy. Human Factors, 47(2), 235-249.

Edwards, J. D., Vance, D. E., Wadley, V. G., Cissell, G. M., Roenker, D. L., \& Ball, K. K. (2005). Reliability and validity of useful field of view test scores as administered by a personal computer. Journal of Clinical and Experimental Neuropsychology, 27, 529-543.

Goode, K. T., Ball, K. K., Sloane, M., Roenker, D. L., Roth, D. L., Myers, R. S., et al. (1998). Useful field of view and other neurocognitive indicators of crash risk in older adults. Journal of Clinical Psychology in Medical Settings, 5(4), 425-438.

McCarley, J. S., Vais, M. J., Pringle, H. L., Kramer, A. F., Irwin, D. E., \& Strayer, D. L. (2004). Conversation disrupts change detection in complex traffic scenes. Human Factors, 46, 424436.

Myers, R. S., Ball, K. K., Kalina, T. D., Roth, D. L., \& Goode, K. T. (2000). Relation of useful field of view and other screening tests to on-road driving performance. Perceptual and Motor Skills, 91, 279-290.

O'Regan, J. K., Rensink, R. A., \& Clark, J. J. (1999). Change-blindness as a result of "mudsplashes." Nature, 398, 34.

Pringle, H. L., Irwin, D. E., Kramer, A. F., \& Atchley, P. (2001). The role of attentional breadth in perceptual change detection. Psychological Bulletin and Review, 8, 89-95.

Rensink, R. A. (2002). Change detection. Annual Review of Psychology, 53, 245-277.

Rizzo, M., Sparks, J. D., McEvoy, S., Batchelder, S., Kellison, I., \& Vecera, S. (submitted). Change blindness in aging and early Alzheimer's disease.

Roenker, D. L., Cissell, G. M., Ball, K. K., Wadley, V. G., \& Edwards, J. D. (2003). Speed-ofprocessing and driving simulator training result in improved driving performance. Human Factors, 45(2), 218-233.

Sanders, A. F. (1970). Some aspects of the selective process in the functional field of view. Ergonomics, 13, 101-117.

Simons, D. J., \& Ambinder, M. S. (2005). Change Blindness: Theory and Consequences. Current Directions in Psychological Science, 14(1), 44-48.

Simons, D. J., Franconeri, S. L., \& Reimer, R. L. (2000). Change Blindness in the absence of a visual disruption. Perception, 29, 1143-1154.

Uc, E. Y., Rizzo, M., \& Anderson, S. W. (2005). Driver landmark and traffic sign identification in early Alzheimer's disease. Journal of Neurology, Neurosurgery and Psychiatry, 76, 764.

Uc, E. Y., Rizzo, M., Anderson, S. W., Shi, Q., \& Dawson, J. D. (2004). Driver route-following and safety errors in early Alzheimer disease. Neurology, 63(5), 832-837. 